\title{
Supervisors' Toxicity As Predictor Of Subordinates' Counter-Productive Work Behavior In Nigerian Public Hospitals
}

\author{
Justin Mgbechi Odinioha Gabriel, Ph.D., Rivers State University of Science and Technology, Nigeria
}

\begin{abstract}
The purpose of this study is to empirically examine the association of Supervisors' Toxicity and Subordinates' Counter-productive Work-behaviour in the Nigerian Public Hospitals. Counter-productive Work -behaviour (criterion variable) is further operationalized using five measures - abuse, production deviation, sabotage, theft, and withdrawal. The cross-sectional survey design is adopted and data is generated using the structured questionnaire. 197 respondents comprising doctors, nursing staff, lab technicians and other administrative staff selected from an accessible population of 402 staff provided responses to the questions. A total of five hypotheses are proposed and tested using descriptive and inferential statistical tools. Results indicate significant relationships in all hypothetical instances, thereby implying an association between Supervisors' Toxicity and Subordinates' Counter-productive Work- behavior. The study therefore concludes that Subordinates are quick to reciprocate Supervisors' Toxicity through Counter-productive Work-behavior of transferring aggression to either peers or otheridentifiable assets of the organization. The study further recommends a more emotionally oriented approach to the management of superior-subordinate relationships with emphasis on the training and retraining of supervisors regarding emotional intelligence as well as conflict and human relations issues.
\end{abstract}

Keywords: Supervisors' Toxicity; Subordinates; Counterproductive behaviour; Nigeria

\section{INTRODUCTION}

Army leaders must set high standards, lead by example, do what is legally and morally right, and influence other people to do the same. They must establish and sustain a climate that ensures people are treated with dignity and respect and create an environment in which people are challenged and motivated to be all they can be.

U.S. Army Field Manual 22-100

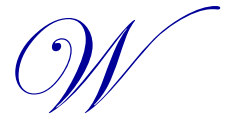

orkplace deviance, counterproductive behavior, antisocial behavior or workplace incivility as it is alternatively referred (Robbins and Judge 2007), is a negative behavior that has been and still currently prevails in many contemporary workplaces. Consequently, counterproductive work behaviour (CWB) has become a popular field of acute interest among many, including; researchers in industrial and organizational studies, managers, business stakeholders and the general public as a whole. Literature has espoused these behaviours as representing a set of distinct acts that share the characteristics of being volitional as opposed to accidental or mandated; having the potentials to harm or intend to harm organizations and/or organization stakeholders, such as clients, co-workers', customers, and supervisors (Fox \& Spector 2005; Spector 2011).

Literature posits that some of these behaviours are:- reading of lotto papers, fidgeting of phones instead of working, abuse of the organization's internet by the downloading non work related materials to list a few. Pradhan and Pradhan (2014) had observed that in the recent wake of several corporate scandals, unethical and deviant workplace behaviour has become a prevalent problem in organization across the world. It has also been estimated that between 33 and 75 percent of all employees have at one point or another engaged in serious or minor deviant behaviours such as theft, 
fraud, vandalism, and sabotage at least once in their professional life (Harper, 1990). Another report mentioned other types of harmful deviant behaviours such as lying (DePaulo \& DePaulo, 1989), spreading rumours (Fox, Spector \& Miles, 2001), withholding effort (Kidwell and Bennett, 1993) and absenteeism (Johns, 1997).

Due to the harsh and enormous socio-economic aftermaths associated with deviance workplace behavior (See Akikibofori, 2013, Appelbaum et al, 2007; Robbinson and Bennet, 1995, Fisher, 2003, Peterson, 2002, Muafy, 2011 and Lawrence and Robbinson, 2007), growing interests has been stimulated among both the academicians and executives in considering its burgeoning prevalence and consequences (Bennett \& Robinson, 2003). In this light, two streams of research have focused on ascertaining the causes of these behaviors. Spector and colleagues (Chen $\&$ Spector, 1992; Fox \& Spector, 1999; Spector 1975, 1978; Storms \& Spector, 1987) have portrayed CWB as an emotion-based response to stressful organizational conditions; whereas Greenberg and colleagues (e.g., Greenberg, 1990, Skarlicki and Folger 1997; Skarlicki, Folger, \& Tesluk, 1999) have taken an organizational justice perspective, viewing CWB as a cognition-based response to experienced injustice. These two perspectives according to Fox, Spector and Miles (2001) are not incompatible, because Spector (1978) noted links with the equity (justice) concept, and Greenberg (1990) also noted links with frustration theory.

Previous research on deviant behavior have focused on organization structure (Yen \& Teng 2013, Henle, 2005), procedural justice (Dineen et al, 2006; Skarlicki \& Folger 1997), work related factors (Ferguson, 2007), personality factors (Fieldman, 2008); and ethical ideology (Henle et al, 2005) as antecedents of deviant workplace behavior and counter productivity. Many of such studies are based on organizational or firm level dynamics. Only a few studies have focused on managers and superiors' pers onality as factors that could promote employee counter productivity and deviant behavior (Lipman-Blue men2005, Kellerman 2004). In this paper, we are looking at counter productive work behaviours through the lens of leadership style, especially, supervisors' toxicity as a predictor of counter productive work behaviors. This study was informed by the scarcity of scholarly attention on the proposed relationship in the Nigerian context. The purpose of the paper therefore is to empirically investigate the association of supervisors' toxicity and subordinates' counterproductive work behaviour in Public Hospitals in Port Harcourt. To achieve this broad purpose, the study shall specifically seek to:

1. Ascertain if supervisors in the Nigerian public hospitals exhibit toxic syndromes at work.

2. Ascertain the as sociation of such toxic behavior and subordinates' abuse of responsibilities.

3. Ascertain the as sociation of toxic behaviors and production deviance

4. Ascertain the as sociation of toxic behavior and subordinates' disposition toward theft of organizations properties.

5. Ascertain the as sociation of toxic behavior and subordinates'sabotage of organisation's interests

6. Ascertain the as sociation of toxic behaviours and subordinates withdrawal from the organization.

\section{LITERATURE}

\section{Supervisors' Toxicity}

Toxicity is derived from the word "toxic". The New Explorer Encyclopedic Dictionary as sociates the word "toxic" to pois on. Hence, anything toxic can be described as poisonous as well, because it reserves the potential to harm its target victim. Positive stories of organizational leaders might highlight leaders who motivate employees to achieve their goals and inspire them to do more than they thought was possible. The negative accounts include stories of leaders who ridicule their employees in public, force employees to endure physical hardships, and promote divisiveness between work groups or individuals. These stories depict behaviors of leaders who inflict serious physical and/or psychological harm on their subordinates while providing supervision at work. It is quite possible that some persons working for these leaders view these same authority figures with respect and admiration while others also perceive them as toxic. These differences in perceptions and attributions suggest we still have much to learn about how people view leadership, since one person's toxic leader may be anotherperson's hero (Lipman-Blu men, 2005).

In Walton's (2007) view, toxic leadership is behavior which is exploitive, abusive, destructive and psychologically and perhaps legalistically — corrupt and poisonous. Schmidt (2008) offered a working definition of toxic leadership 
that: toxic leaders are those who: (1) display a wide range of extreme emotions in an unpredictable pattern (2) lack emotional intelligence (3) act in ways that are culturally and/orinterpersonally Insensitive (4) are primarily motivated by self-interest (5) influence others by employing negative managerial techniques (for example: micromanagement that is, not having trust on subordinates' ability to finish tasks unsupervised). Accordingly, these behavior are exemplified as-the forced imposition of unrealistic workloads as prevalent in the marketing targets given to bankers in Nigeria, workplace bullying and harassment, deception and fraud in addition to deliberate workplace misinformation and misrepresentation.

Lipman- Blumen (2005) further describes corruption, hypocrisy, sabotage, manipulation, as well as other assorted unethical, illegal, and criminal acts to be part of the poisonous repertoire of toxic leaders. One major difficulty, however, is how to differentiate between toxic leadership and over-zealous leadership as many of the attributes toxic leaders possess, when not used to excess or inappropriately, are the same as those exhibited by successfulnon-toxic leaders. The situation is further complicated as some behaviours — now acknowledged as toxic — may have previously been excused, denied, or even encouraged, because of the results delivered and this may have (i) reinforced the 'acceptability' of such behaviour, (ii) encouraged its continuing use, (iii) discouraged others from challenging the unacceptable behaviours experienced, and (iv) generated a groupthink and/or acceptant mentality offering little possibility for improvement (Janis, 1982).

Toxic leaders can have great appeal, and attract followers, because of the high level of engagement and energy they display. They will 'make it happen', 'get things done', sort out 'the road block', 'cut away the dead wood' —yet how they may go about this can be profoundly damaging to many around them and, potentially, to the business itself. Indeed the literature is awash with suggestions that the most frequently reported dis ruptive executive behaviours are characterized by dramatic, histrionic, emotionally demanding, narcissistic, aggres sive and somewhat grandiose leadership behaviours (Conger, 1990; Dotlich \& Cairo, 2003; Finkelstein, 2003; Kellerman, 2004). In his study however, Scmidth (2008) developed six dimensions of toxicity which we consider appropriate here; they are:

- Abusive Supervision: involves leaders' hostile verbal and nonverbal behaviors to their subordinates. Examples of such behaviors include public demonstrations of anger, personal ridicule, and destructive feedback. This does not include physicalabuse.

- Authoritarian Leadership: involves leader behaviors that restrict subordinate autonomy and initiative. Toxic leaders micromanage their subordinates. It is "their way or the highway". They do not empower their staff to take sole ownership of work and are often unwilling to delegate anything except the most basic, routine work. Authoritarian leaders demand total compliance with their own agendas and operating procedures.

- Self-Promotion: involves behaviors that promote leaders' own interests (especially to higher level superiors) and that decrease threats from rivals and/or talented subordinates.

- Unpredictability: involves enacting a wide range of behaviors that reflect dramatic shifts in mood states. This is further explained by the fact that toxic leaders easily switch mood, they are warm and welcoming one moment, then vicious and cruel the next. Employees are by this behaviorkept confused, not knowing the behavior to expect, and this unpredictability keeps everyone on edge all the time. In fact, this creates a psychological effect that was earlier described as "learned helplessness", (Seligman, 1967).

- Unprofessional Behaviors: show that leaders lack task competence, personal and professional integrity, and collegial respect for peers and subordinates.

- Narcissism: involves having a grandiose self-image, an inability to empathize with others, and contempt for the abilities and efforts of others. They often ignore and minimize their employees' suggestions, assuming that if the idea is not theirs, it is simply not good. Toxic leaders also assume they are above the rules and blatantly ignore policies. But of course, they expect everyone else to follow standard procedures.

Management scholars and practitioners have increasingly identified interrelationships between leadership and organizational dysfunction (e.g. see Frost, 2003; Kellerman, 2004; Levinson, 1972, 1976; Lowman, 2002; Lubit, 2004; 
Fox and Spector, 2005); notably absent in the analys is of dysfunction is an explicit, systematic examination of high toxicity leadership and its impact upon organizational systems (e.g. see Goldman, 2005).

\section{Counter Productive Work Behavior}

Counter productive work behavior (CWB) can be described as volitional behavior that harms or contains the potentials to harm organizations or their stakeholders (Fox and Spector, 2005; Spector, Bauer and Fox, 2010; Spector, Fox, Penney, Bruursema, Goh, and Kesler, 2006). Researchers have given these behaviors many different names; including workplace deviance counterproductive behavior, antisocial behavior (Appeibaum and Matousek (2007), and workplace incivility Robinson and Judge (2007). According to Robinson \& Bennet (1995) typology, workplace deviance varies along two dimensions, namely 'interpersonal versus organizational' and 'minor versus serious'.

The result of Robinson and Bennett's res earch established a two dimensional chart which organizes counterproductive workplace behavior into four quadrants labeled: production deviance, property deviance, political deviance and personal aggression, see Figure 1. Organizational deviance is a grouping of behaviors between the individual and the organization that involves things such as theft, sabotage, lateness, or putting little effort into work. On the other hand, interpers onal deviance is a behavior displayed between individuals in the workplace and involves behaviors such as: belittling others, playing pranks on others, acting rudely, arguing, and physical aggression, the first dimension typology which is the organizational-interpersonal dimension, has the axis ranges from deviance directed towards individuals to deviance directed towards the organization.

Figure 1. Typology of negative deviant workplace behavior

\begin{tabular}{|c|c|}
\hline $\begin{array}{l}\text { Production Deviance } \\
\text { * } \quad \text { Leaving early } \\
\text { * Taking excessive beaks } \\
* \quad \text { Intentionally working slow } \\
\text { * Wasting Resources } \\
\text { MINOR } \\
\quad \text { Political Deviance } \\
\text { * Showing favoritism } \\
\text { * Gossiping about co-workers } \\
\text { * Blaming co-workers } \\
\text { * Competing non beneficially }\end{array}$ & $\begin{array}{l}\text { Property Deviance } \\
\text { * Sabotage equipment } \\
\text { * Accepting Kickbacks } \\
\text { * Lying about hours worked } \\
\text { * Stealing from company } \\
\text { Personal Aggression } \\
\text { * Sexual Harassment } \\
\text { * Verbal abuse } \\
\text { * Stealing from co-workers } \\
\text { * Endangering co-workers } \\
\text { ONAL }\end{array}$ \\
\hline
\end{tabular}

Similarly, Chand and Chand (2014) used the following to measure CWB:

- Abuse -this consist of harmful behaviours directed at coworkers and others that harm either physically or psychologically through making threats, nasty comments, ignoring the person, or undermining the person's ability to work effectively.

- Production deviance: it is the purposeful failure to perform job tasks effectively the way they are supposed to be performed.

- Sabotage: it involves defacing or destroying physical properties belonging to the employer; intentional wasting of the material in the organization and purposely dirtying or littering of the workplace. 
- Theft: stealing something belonging to the employer and delaying role performance to attract extra pay or other kinds of rewards.

- Withdrawal: this consists of behaviors that restrict the amount of time working to less than is required by the organization. It includes absence, arriving late or leaving early, and taking longer brakes than is approved. In the study of Rishipal (2012), different levels of managers have been compared for managerial effectiveness and counterproductive work behaviours. Findings revealed that they differ significantly in their mean values with respect to their psychological characteristics of CWB and managerial effectiveness as well as there is significant correlation between the tendency of CWB and managerial effectiveness among the different levels of managers.

\section{Supervisors' Toxicity and Subordinates' Counterproductive Work Behaviour}

The consequences of destructive, toxic leadership behaviors at the organizational and subordinate level are ubiquitous. Subordinates look up to their managers who they see as leaders; the actions or inactions of these managers have direct and indirect consequences on subordinates' attitude to work. At the organizational level, researchers have found increases in workplace deviance by subordinates who report working for abusive supervisors (Mitchell and Ambrose, 2007). These counterproductive behaviors tend to be attributed to negative reciprocity, that is, the employee's effort to 'balance the scale' of perceived injustice by inflicting harm back onto the company. Retaliatory behaviors can include sabotaging operations, providing inaccurate or mis leading information, and withholding citizenship behaviors (Aquino et al., 2001; Bies and Tripp, 1996; Tripp et al., 2002).

Reed (2004) introduced the negative consequences of toxic leadership in a military context by articulating that these leaders erode unit cohesion and deflates es prit de corps. At the individual level, studies have shown abusive leadership to be positively related to turnover intentions and psychological distress, and related negatively to affective and continuance commitment, job and life satisfaction (Rayner and Cooper, 1997; Tepper, 2000; Tepper, Duffy, Hoobler and Endsley, 2004; Aryee, Sun, Chen, and Debrah, 2007). Further, employees subjected to leaders who attack their self-esteem tend to feel low self-worth and diminished sense of self-efficacy (Kusy and Holloway, 2009) that could lead to deteriorations in performance and morale. It is based on the foregoing that we hypothesize that:

Ho1: Supervisor's toxicity has positive and significant association with five measures of counter productive work behavior.

These hypothesized relationships are further depicted in a conceptual model. See Figure 2.

Figure 2. Operational framework of the study

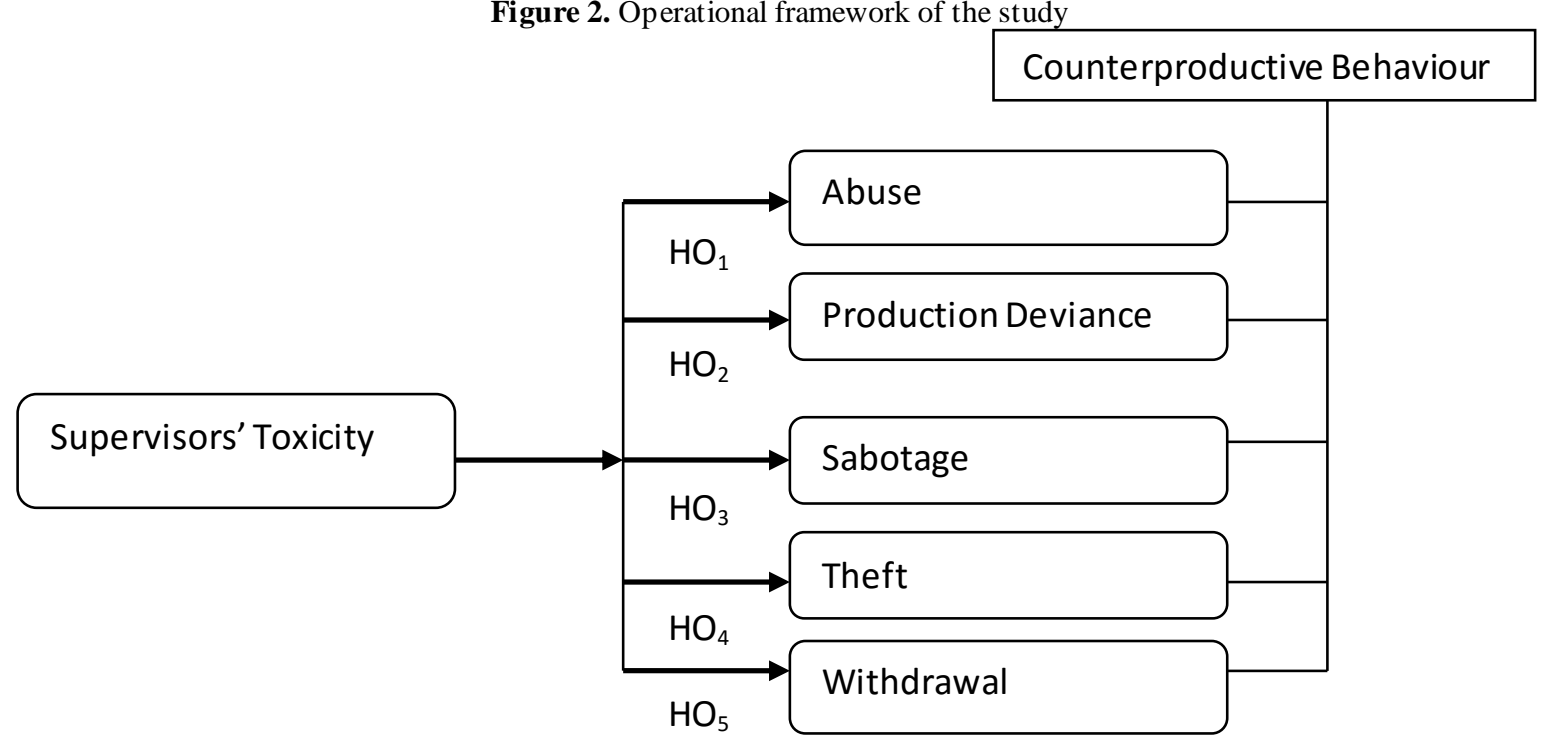


Figure 2 illustrates the operational framework for the study upon which the following hypotheses are postulated:

Ho1: There is no significant relations hip between supervisors' toxicity and abuse among subordinates of Nigeria public hospitals

Ho2: There is no significant relationship between supervisors' toxicity and production deviance among subordinates of Nigeria public hospitals

Ho3: There is no significant relationship between supervisors' toxicity and sabotage among subordinates of Nigeria public hospitals

Ho4: There is no significant relationship between supervisors' toxicity and theft among subordinates of Nigeria public hospitals

Ho5: There is no significant relationship between supervisors' toxicity and withdrawal among subordinates of Nigeria public hospitals

\section{METHODS}

\section{Population and Sampling}

The population of the study comprises four hundred and seventy one (471) workers of four hospitals namely Braithwaite Memorial Hospital, University of Port Harcourt Teaching Hospitals, First Rivers Clinic and New Mile One Hospital with a sampling frame encompassing Doctors, nursing staff, lab technicians and other administrative staff within the target hospitals. The Taro Yamane's (1967) formula was used to obtain a sample size of 216 participants while sampling was achieved using the simple random sampling method based on the homogenous nature of the sub-populations being hospitals (see Okpu \& Kpakol, 2015).

\section{Measurement and Instrumentation}

The survey instrument is the structured questionnaire with the scale for the predictor variable - supervisors' toxicity, adapted from the work of Schmidt (2008) while the scale for the criterion variable - counterproductive behaviour is adapted from the work of Chand and Chand (2014) with five dimensions namely - abuse, production deviance, sabotage, theft and withdrawal. Variables are scaled on a five point scale of (1) strongly disagree (2) disagree (3) undecided (4) agree (5) strongly agree.

\section{Reliability}

The Cronbach alpha reliability was adopted in estimating the internal reliability of the instruments. The results are presented in table 1. Below:

Table 1. Cronbach reliability coefficients

\begin{tabular}{l|c|c}
\hline \multicolumn{1}{c}{ Variables } & No. of items & Alpha coefficients \\
\hline Supervisors' toxicity & 7 & .839 \\
\hline Abuse & 5 & .830 \\
\hline Production deviance & 5 & .715 \\
\hline Sabotage & 5 & .800 \\
\hline Theft & 5 & .884 \\
\hline Withdrawal & 5 & .776 \\
\hline
\end{tabular}

Source: Research data, 2015 


\section{RESULTS}

\section{Survey}

Questionnaire copies were personally administered to the respective public hospitals and followed up as a result of proximity to the researcher. Distribution and retrieval of copies within the selected hospitals was carried out through the assistance of various administrative correspondences who served as contact points in the target hospitals. Out of a total of $216(100 \%)$ copies of the questionnaire distributed, $197(91 \%)$ copies were successfully retrieved and utilized in the data analysis.

\section{Demographic}

The target of analysis was the individual staff members of the target hospitals as these members served as units of measurement in the study. The sample characteristics revealed that out of a total of 197 participants; 104 (53\%) were female and $93(47 \%)$ male; $56(28 \%)$ doctors, 111 (56\%) Nurses, $17(9 \%)$ lab technicians and $13(7 \%)$ administrative staff; while for experience and tenure with the particular hospital of work, 77 (39\%) of the participants had worked with their respective hospitals for more than fifteen (15) years, 85 (43\%) had worked between ten (10) to fifteen (15) years, while only $35(18 \%)$ had worked for less than ten (10) years. The detailed distribution is described in Figure 3 below:

Figure 3. Bar Chart for Demographics

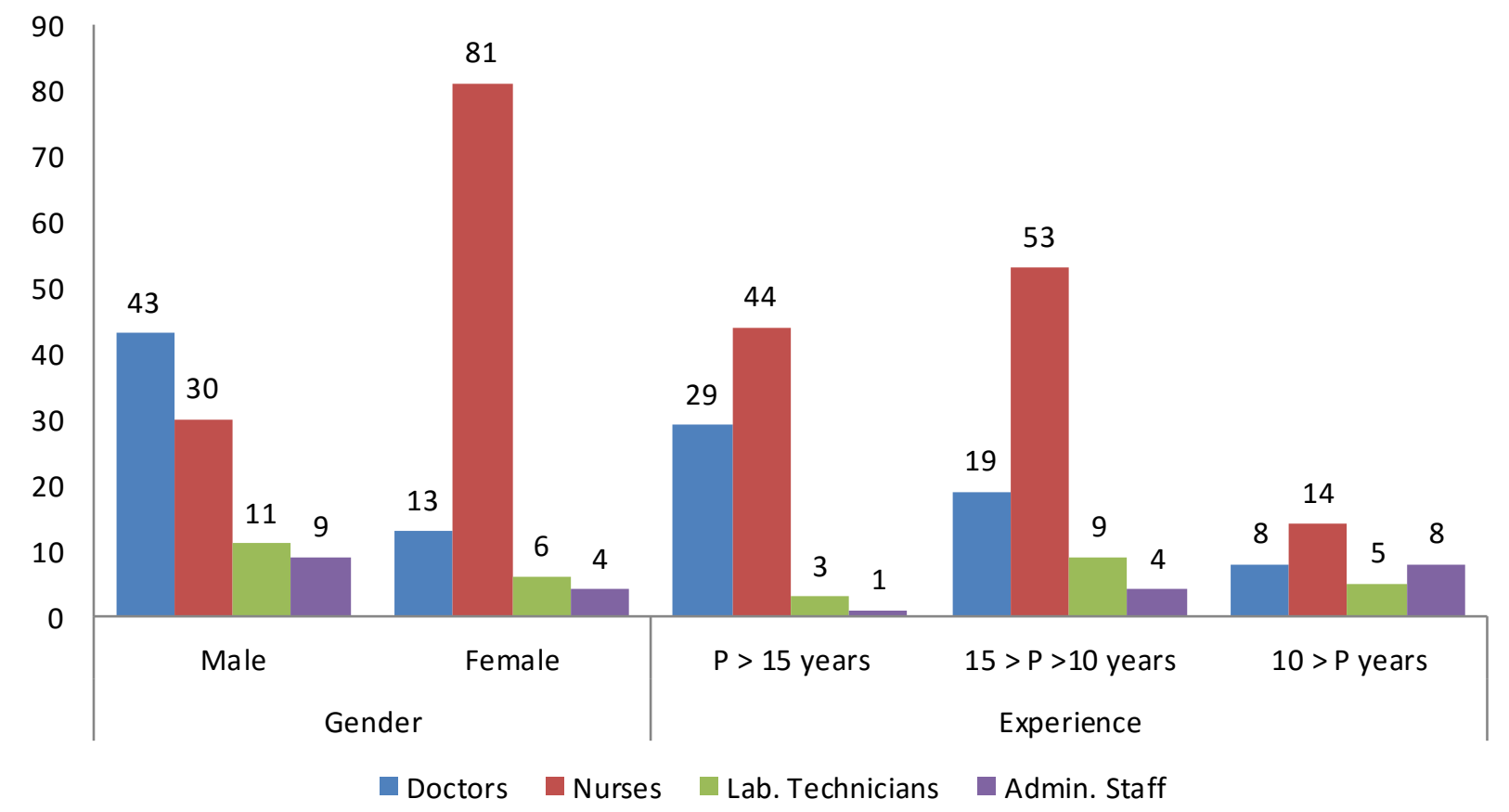

Where $\mathrm{P}=$ experience; $\mathrm{P}>15$ years = experience of more than 15 years $; 15>\mathrm{P}>10$ years $=$ experience of between $10-15$ years; $10>\mathrm{P}=$ experience of less than 10 years.

The descriptive analysis for the variables examines the central tendency and variability of responses using the mean $(x)$ and standard deviation $(s)$. A base mean of $\mathrm{x}>3.0$ is adopted in the identification of agreement levels to indicators which are all stated in the positive while $\mathrm{x} \leq 3.0$ is adopted as an indication of disagreement levels to the indicators. $\mathrm{n}$ $=197$; and confidence interval is set at $95 \%$. Analysis is carried out using the Pearson Product Moment Correlation Coefficient Test. 
Table 2. Descriptive and correlation results

\begin{tabular}{l|l|l|l|l|l|l|l|l}
\hline & Mean $(\boldsymbol{x})$ & $\mathbf{S D}(\boldsymbol{S})$ & $\mathbf{1}$ & $\mathbf{2}$ & $\mathbf{3}$ & $\mathbf{4}$ & $\mathbf{5}$ & $\mathbf{6}$ \\
\hline Toxicity & 3.8942 & .69901 & & & & & \\
\hline Abuse & 3.9076 & .86224 & $.652^{* *}$ & & & & \\
\hline Deviance & 3.9543 & .68997 & $.421^{* *}$ & $.674^{* *}$ & & & \\
\hline Sabotage & 3.8487 & .74427 & $.975^{* *}$ & $.681^{* *}$ & $.370^{* * *}$ & & \\
\hline Theft & 3.9208 & .93951 & $.722^{* *}$ & $.964^{* *}$ & $.575^{* *}$ & $.758^{* *}$ & & \\
\hline Withdraw & 3.9442 & .73757 & $.399^{* *}$ & $.734^{* *}$ & $.948^{* *}$ & $.354^{* *}$ & $.598^{* *}$ & \\
\hline
\end{tabular}

Where $\mathrm{p}<.05^{*}=$ significance at a 0.05 level; and $\mathrm{p}<.01^{* *}=$ significance at a 0.01 level.

Table 2. above illustrates the output for the descriptive and correlation analysis on the variables with mean $(x)$ values indicating average levels of agreement on all six (6) variables while the standard deviation $(s)$ for all variables carry low values of $\mathrm{s}<1.0$ and $r$ values indicating significance at a $\mathrm{p}<.01$ level.

Ho1: Supervisors' toxicity is not significantly as sociated with abuse

Findings reveal a significant relationship between supervisors toxicity and abuse with an $\mathrm{r}=.652$ and a probability value $\mathrm{p}<0.01$ significant at a 0.01 level. Based on the findings, the hypothetical statement of no relationship is hereby rejected as the findings reveal a significant and strong relationship between supervisors' toxicity and abuse. This implies that outcomes of abusive behaviour as expressed within the organization are closely linked to toxic supervis ory actions, attitudes and personality.

Ho2: Supervisors' toxicity is not significantly associated with production deviance

The results indicate a significant association between supervis ors toxicity and production deviance with an $r=.421$ and a probability value $\mathrm{p}<0.01$ significant at a 0.01 level. Therefore the previous tentative statement of no relationship between both variables is rejected implying a link between supervisors toxicity and production deviance within the organization.

Ho3: Supervisors' toxicity is not significantly associated with sabotage

The findings reveal a significant relationship between supervisors toxicity and sabotage with an $r=.975$ and a probability value $\mathrm{p}<0.01$ significant at a 0.01 level. The coefficients suggest this is a strongeras sociation relative to other instances therefore the previously hypothesized statement of no relationship is hereby rejected as the findings reveal a significant and strong relationship between supervisors' toxicity and sabotage; thus implying that incidences of purposive sabotage within the organization are closely linked to toxic supervisory actions, attitudes and pers onality.

Ho4: Supervisors' toxicity is not significantly as sociated with theft

The findings show that there is a significant relationship between supervis ors toxicity and theft with an $\mathrm{r}=.722$ and a probability value $\mathrm{p}<0.01$ significant at a 0.01 level; based on these result the previously hypothesized statement of no relationship is hereby rejected as the findings reveal a significant and strong relationship between supervisors' toxicity and theft; thereby implying a correlation between supervisors toxicity and theft at the workplace.

Ho5: Supervisors' toxicity is not significantly as sociated with withdrawal

The results of the analysis reveal a significant relationship between supervisors toxicity and withdrawal with an $\mathrm{r}=$ .399 which is the weakest level of as sociation compared to other relative instances with a probability value $p<0.01$ significant at a 0.01 level; based on this result the previously hypothesized statement of no relationship is hereby rejected as the findings reveal a significant and strong relationship between supervisors' toxicity and withdrawal; thereby implying an as sociation between supervisors toxicity and withdrawal at the workplace. 
Figure 4. Line graph showing mean correlation between supervisors' toxicity and counterproductive behaviour

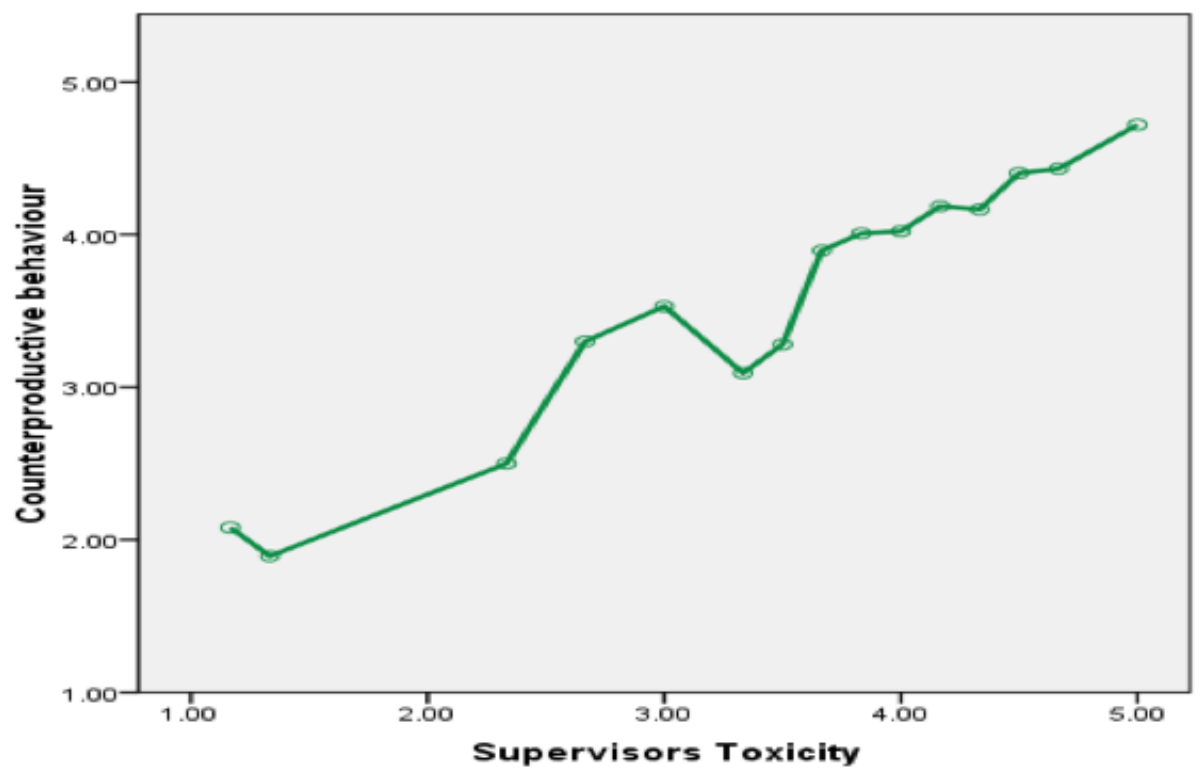

Figure 4 illustrates the association between supervisors' toxicity and counterproductive work behaviour based on mean values. The diagram summarizes the correlation tests for both variables as points indicate as sociated mean values relative to both variables.

\section{DISCUSSION AND CONCLUS IONS}

The objective of this study was the empirical assessment of the association between supervisors' toxicity and counterproductive work behaviour in Nigerian public hospitals. This study observed the presence of toxic postures among superordinates of the organizations under focus. Such result is in clear tandem with Jaja's (2000, 2015); who argued that subordinates are in the want of comfort, stability, and solutions from their managers, but that such expectations appear as an optical illusion in the African workplace because African managers rather prefer to knock their subordinates out of their comfort zone through toxic tendencies. Consequently, the prevalence of toxic dispositions among supervisors was observed to have significant relationships with all five measures of counterproductive work behavior namely - abuse, production deviance, sabotage, theft and withdrawal. Although all relationships are significant; The results reveal higher levels of correlation between supervisors' to xicity and sabotage; and supervisors' toxicity and theft; implying a tendency for subordinates to "hit back" through destructive activities .

The findings are further corroborated by the studies of Aquino et al., (2001) and Tripp et al., (2002) in which instances of retaliatory actions are considered reciprocal to perceived forms of maltreatment and injustice at the workplace. Subordinates; as suggested by the findings; would most likely opt for counterproductive actions as self-gratification alternatives when confronted with toxic behaviour as expressed by managers or supervisors. Implications are that; although such actions may not be confrontational; they would purposively aim at inflicting losses, damage and waste. Most importantly, innocent patients and their relatives bear the brunt of these counterproductive work behaviours because affected workers often would transfer their frustration on them.

In conclusion, we find that supervis ors' toxicity at the workplace is often times reciprocated through counterproductive behaviour which are adopted as a means of payback for treatments deemed abusive, degrading or insulting. Subordinates are prone to transferring aggression to either peers or identified properties and assets of the hospital accompanied by actions ranging from outright sabotage to destruction of hos pital property, theft, withdrawal and an inclination towards continuance commitment. On the reverse, treating employees with sense of humanization as 
observed by Gabriel et al (2015) would encourage them to display positive behaviors at work because it effectively communicates that they are valued and trusted and that they are important to the organisation.

\section{RECOMMENDATIONS}

- Steps should be taken to train managers within the context of dealing emotionally with subordinates and creating an atmosphere of mutual respect both for authority and individual contributions.

- Bosses should not by their conducts dehumanize their subordinates because the consequences can be very detrimental against the organization at large.

- Organizations should train their staff on skills that will enable them develop emotional resilience so that they can absorb the toxic syndromes of difficult bosses.

- Organizations must create an atmosphere that guarantees subordinate safety if they report toxic behaviors of their superiors to management.

- Supervisors who are found to be toxic in dealing with subordinates must be made to face severe consequences ranging from negative appraisal to any other organizationally applicable discipline.

\section{REFERENCES}

Akikibofori, J. S. (2013). Workplace deviant behaviors: a case study of Intels Nigeria limited. Research in Humanity and Social Sciences, 3(22):49-56.

Appelbaum. S.H, Laconi, G.D, \& Matousek. A. (2007), Positive and negative deviant workplace behaviors: causes, impact, and solutions, Corporate, $l$ 7(5): 586-598

Aquino, K, Tripp, T.M. and Bies, R.J. (2001). How employees respond to personal offense: The effects of blame, attribution, victim status, and offender status on revenge and reconciliation in the workplace. Journal of Applied Psychology 86(1): $52-59$.

Aryee, S., Sun, L., Chen, Z. X., and Debrah, Y. A. (2007). Antecedents and outcomes of abusive supervision: Test of a trickledown model. Journal of Applied Psychology, 92, 191-201.

Bennett, R. J. \& Robinson, S. L. (2003). The past, present, and future of workplace deviance research, in organizational behavior: The State of the Science, ed. J. Greenberg . Mahwah, NJ: Erlbaum.

Chand, P and Chand, P.C. (2014). Job stressor as predictor of counter productive work behavior in Indian banking sector, International Journal of Engineering and Management (IJAIEM) 3(12):2319-4847.

Conger, J. (1990) “The dark side of leadership". Organizational Dynamics, 19, 44-55.

DePaulo, P.J., \& DePaulo, B.M. (1989). Can deception by salespeople and customers be detected through nonverbal behavioural cues?,Journal of Applied Social Psychology, 19, 1552-1577.

Dineen, B. R., Lewicki, R. J., \& Tomlinson, E. C. (2006). Supervisory guidance and behavioral integrity: relationships with employee citizenship and deviant behavior. Journal of Applied Psychology. 91,(3); 622-635.

Dotlich, D. \& Cairo, P. (2003) Why CEOs fail. Jossey-Bass Publishers, San Francisco.

Fox, S. and Spector, P. (2005), Counterproductive work behavior: Investigations of actors and targets, American Psychological Association, Washington, DC.

Fox, S., Spector, P. E. \& Miles, D. (2001).Counterproductive work behaviour (CWB) in response to job stressors and organizational justice:some mediator and moderator tests for automy and emotions". Journal of Vocational Behaviour, 59,291-309.

Finkelstein, S. (2003) Why smart executives fail, Portfolio. Penguin Books. New York.

Fox, S., Spector, P. E.\& Miles, D. (2001). Counterproductive work behavior (CWB) in response to job stresssors and organizational justice: Some mediator and moderator tests for autonomy and emotions. Journal of Vocational Behavior, 59(3), 291-309.

Frost, P. (2003), Toxic emotions at work, Harvard Business School Press, Boston, MA.

Fisher, C. D. (2003). Why do lay people believe that satisfaction and performance are correlated? Possible sources of a commonsense theory. Journal of Organizational Behavior, 24(6), 753-777

Greenberg, J. (1990). Employee theft as a reaction to pay inequity: The hidden cost of pay cuts. Journal of Applied Psychology, $75,561-568$.

Gabriel, J.M.O., Nwaeke, L. I. (2015). Non-financial incentives and job satisfaction among hotel workers in Port Harcourt, Journal of Scientific Research and Reports, 6(3): 228-236.

Harper, D. (1990). Spotlight abuse - Save profits. Industrial Distribution, 79, 47-51.

Jaja, S. A. (2000). Managing work alienation in formal organization: The Nigerian experience, International Journal of Economic and Development Issues, 2(2): 115-140.

Copyright by author(s); $\underline{\text { CC-BY }}$ 
Jaja, S. A. (2015). Breaking the management coconut: Do y ou see crumbling pillars or an ark? Being an inaugural lecture delivered on September $30^{\text {th }} 2015$ at the $37^{\text {th }}$ inaugural lecture of Rivers State University of Science and Technology, Nkpolu Oroworukwo, Port Harcourt.

Janis, I. (1982) Groupthink, Boston, Houghtin Mifflin Company.

Johns, G. (1997). Contemporary research on absence from work: correlates, causes, and consequences, In Cooper, C.L. and Robertson, I.T. (Eds.), International Review of Industrial and Organisational Psychology, 12, John Wiley \& Sons, London, 115-174.

Kellerman, B. (2004) Bad Leadership, HBS Press, Boston.

Kidwell, R. E., \& Bennett, N. (1993). Employee propensity to withhold effort: A conceptual model to intersect three avenues of research. Academy of Management Review, 18, 429-456.

Kusy, M. and Holloway, E. (2009). Toxic workplace: Managing toxic personalities and their systems of power. San Francisco: Jossey-Bass.

Lawrence,T.B. \& Robinson. S.L, (2007), Ain't misbehavior workplace resistance. Journal of Management, 33(3), 378-394

Levinson, H. (1972). Organizational diagnosis, Harvard University Press, Cambridge, MA.

Levinson, H. (1976). Psy chological Man, Levinson Institute, Boston, MA.

Lipman-Blumen, J. (2005) The Allure of Toxic Leaders, Oxford University Press Inc. New York.

Lowman, R. (Ed.) (2002), Handbook of Organizational Consulting Psychology, Jossey-Bass, San Francisco, CA.

Lubit, R. (2004), Coping with Toxic Managers, Subordinates and Other Difficult People, Prentice Hall Financial Times, Englewood Cliffs, NJ.

Mitchell, M.S. and Ambrose, M.L. (2007). Abusive supervision and workplace deviance and the moderating effects of negative reciprocity beliefs. Journal of Applied Psychology 92(4): 1159-1168.

Muafi, J. (2011). Causes and consequences of deviant workplace behavior. International Journal of Innovation, Management and Technology, 2(2), 123-126.

Okpu, T.\& Kpakol, A.G (2015). Managing employ ee trust perceptions for sustained workplace harmony in the Nigerian banking industry. International Journal of Managerial Studies and Research: 3 (5) 65 - 73.

Peterson, F. (2010). Deviant workplace behaviour and the organization's ethical climate. Journal of Business and Psychology, I 7(1).47-56.

Pradhan, S. and Pradhan, R. K. (2014). Transformational leadership and deviant workplace behaviours: the moderating role of organizational justice, Proceedings of the first asian-pacific conference on global business, economics, finance and social sciences, $1-19$. Retrieved $14^{\text {th }}$ march, 2015 at www.globalbizresearch.org.

Rayner C and Cooper C (1997) Workplace bullying: Myth or reality - Can we afford to ignore it?Leadership and Organization Development Journal 18(4): 211-214.

Reed, G.E. (2004). Toxic leadership. Military Review, JUL-AUG, 67-71.

Robbins, S.P. \& Judge, T. A. (2007), Organizational behavior, Twelfth Edition, Pearson Education, Inc., Upper Saddle, River, New Jersey.

Robinson, S.L. \& Bonnet, R.J. (1995). A Typology of deviant workplace behaviors: A Multidimensional Scaling Study. The Academy of Management Journal, 38 (2), 555-572

Seligman, M.E. P. and Maier, S. F. (1967). Failure to escape traumatic shock. Journal of experimental psychology, 74, 1-9.

Sutton RI (2007) The no asshole rule: Building a civilized workplace and surviving one that isn't.New York: Warren Business Books.

Schmidt, A. A. (2008). Development and validation of the toxic leadership scale. Thesis submitted to the faculty of the graduate school of the university of Maryland, college park, in partial fulfillment of the requirements for the degree of master of science

Skarlicki, D. P. and Folger, R. (1997). Retaliation in the workplace: The role of distributive, procedural, and interactional justice. Journal of Applied Psychology 82: 434-443

Tepper, B. (2000), “Consequences of abusive supervision”, Academy of Management Journal, 43 (2): 178-90

Tepper, B. J., Duffy, M. K., Hoobler, J., and Ensley, M. D. (2004). Moderators of the relationship s between coworkers' organizational citizenship behavior and fellow employ ees' attitude. Journal of Applied Psychology, 89, 455-465.

Tripp TM, Bies RJ and Aquino K (2002) Poetic justice or petty jealousy? The aesthetics of revenge. Organizational Behavior and Human Decision Processes 89(1): 966-984

Walton, M. (2007). Toxic leadership: an inevitable affliction of organizations? Organisation and People, 14(1): 19-26

Yen, C. and Teng, H. (2013). The effect of centralization on organizational citizenship behaviour and deviant workplace behaviour in the hospitality industry. Tourism Management. 36: 401-410 


\section{NOTES}

